$1-31-2014$

\title{
The Odd-Ending Price Justification Effect: The Influence Of Price Endings On Hedonic And Utilitarian Consumption
}

Jungsil Choi

Cleveland State University, j.choi59@csuohio.edu

Yexin J. Li

Priyamvadha Rangan

SUNY, Brockport

Promothesh Chatterjee

Follow this and additional works at: https://engagedscholarship.csuohio.edu/bus_facpub

Part of the Advertising and Promotion Management Commons, and the Marketing Commons How does access to this work benefit you? Let us know!

\section{Publisher's Statement}

The final publication is available at Springer via http://dx.doi.org/10.1007/s11747-014-0369-6

\section{Original Published Citation}

Choi, J., Li, Y.J., Rangan, P., Chatterjee, P., \& Singh, S.N. (2014). The odd-ending price justification effect: The influence of price-endings on hedonic and utilitarian consumption. Journal of the Academy of Marketing Science, 42(5), 545-557. doi:10.1007/s11747-014-0369-6

This Article is brought to you for free and open access by the Monte Ahuja College of Business at EngagedScholarship@CSU. It has been accepted for inclusion in Business Faculty Publications by an authorized administrator of EngagedScholarship@CSU. For more information, please contact library.es@csuohio.edu. 


\title{
The odd-ending price justification effect: the influence of price-endings on hedonic and utilitarian consumption
}

\author{
Jungsil Choi • Yexin Jessica Li • Priyamvadha Rangan • \\ Promothesh Chatterjee • Surendra N. Singh
}

\begin{abstract}
This paper examines how odd-ending pricing influences consumption of hedonic and utilitarian products. Four studies test the hypothesis that the discount image associated with odd-ending prices reduces anticipated guilt and provides justification for hedonic consumption - an effect the authors label the odd-ending price justification effect (OPJE). Study 1 reveals people are more likely to choose hedonic over utilitarian products when they have odd-ending prices. Study 2 finds that the effect of odd-ending prices on hedonic consumption is mediated by guilt reduction. Study 3 reveals a boundary condition for the OPJE - purchase likelihood of hedonic products increases only when monetary, not nonmonetary, guilt is reduced. Study 4 suggests the OPJE operates at an unconscious level, as consumers who are made aware of the trivial difference between odd- and round-ending prices are no longer influenced by odd-ending prices. The theoretical, practical, and research implications of these findings are discussed.
\end{abstract}

J. Choi $(\bowtie)$

Monte Ahuja College of Business, Cleveland State University, 2121

Euclid Ave, Cleveland, OH 44115, USA

e-mail: jungsilchoi@gmail.com

Y. J. Li $\cdot$ P. Rangan $\cdot$ P. Chatterjee $\cdot$ S. N. Singh

University of Kansas, 1300 Sunnyside Ave, Lawrence, KS 66045 , USA

\author{
Y. J. Li \\ e-mail: jessica.li@ku.edu \\ P. Rangan \\ e-mail: priyam@ku.edu \\ P. Chatterjee \\ e-mail: chatterjee@ku.edu \\ S. N. Singh \\ e-mail: ssingh@ku.edu
}

Keywords Odd-ending pricing $\cdot$ Motivation $\cdot$ Hedonic consumption $\cdot$ Justification effect

Imagine a product being sold in two different retail outlets for $\$ 99.99$ (odd-ending price) and $\$ 100.00$ (round-ending price). For all practical purposes, the price difference of $\$ 0.01$ should not influence purchase decisions. However, extensive research (e.g., Choi et al. 2012; Kalyanam and Shively 1998; Manning and Sprott 2009; Schindler and Kibarian 1996; Stiving and Winer 1997) and the widespread use of oddending prices by retailers (Holdershaw et al. 1997) suggest that consumers are more likely to buy the product that is priced at $\$ 99.99$ than $\$ 100.00$. But what if that product is a much-needed microwave oven rather than a beautiful, but unnecessary, designer watch? That is, does the effectiveness of odd-ending pricing change depending on whether the product is utilitarian or hedonic?

In the current research, we propose that odd-ending pricing is especially effective for hedonic consumption because it serves as justification for such purchases. Hedonic products are often thought of as more discretionary than utilitarian products (Okada 2005). Thus, consumers feel a need to justify their decision to buy a hedonic product and feel guilty if they cannot. We argue that because odd-ending prices are perceived as price discounts, they can be used as justification for hedonic consumption, reducing anticipated guilt and increasing the likelihood of purchase.

Below, we review the pertinent literature on hedonic and utilitarian products to explore why some purchases need justification more than others. We also review the literature on odd-ending prices to examine when and why this pricing strategy is effective. Based on a synthesis of this review, we formulate our hypotheses and systematically test them in a series of experiments. Finally, we discuss the implications of our findings and prospects for further research. 


\section{Theoretical background}

Guilt and hedonic consumption

Strahilevitz and Myers (1998) classify consumption into two categories based on their affective content and motives. Utilitarian consumption is motivated by the desire to satisfy a functional or sensible need, and is often labeled "practical" or "necessary" in Western culture.

Examples of utilitarian goods include microwaves, detergents, minivans, home security systems, and personal computers (Hirschman and Holbrook 1982; Strahilevitz and Myers 1998; Wertenbroch and Dhar 2000). Hedonic consumption, on the other hand, is motivated mostly by the desire to satisfy a need for fantasy, fun, and pleasure and is often thought of as "frivolous" or "decadent" in Western culture. Designer clothes, sports cars, luxury watches, and chocolate are often thought of as hedonic products.

Hedonism and utilitarianism are not necessarily two ends of a one-dimensional scale (Okada 2005; Voss et al. 2003). A product may be high and low on both hedonic and utilitarian attributes (Batra and Ahtola 1991; Crowley et al. 1992), though its aggregate perception could be singularly hedonic or utilitarian (Wertenbroch and Dhar 2000; O'Curry and Strahilevitz 2001) and, compared to utilitarian consumption, hedonic consumption is thought of as more discretionary (Okada 2005). For instance, a pair of shoes can appeal to a consumer for both its functional features (e.g., durability) as well as its hedonic features (e.g., looks). Thus, in line with Pham (1998) we recognize that both usage and consumption goals determine whether a product is perceived as primarily hedonic or utilitarian.

Hedonic purchase decisions are often more difficult than utilitarian ones because consumers anticipate feeling guilt. This guilt can be a great barrier in consumer decision making. Furthermore, guilt reduces the positive feelings derived from hedonic consumption, and makes purchases less satisfying (Prelec and Loewenstein 1998). Therefore, dealing with consumption guilt is a critical challenge for companies selling hedonic products/services. Previous research indicates three ways consumers mitigate guilt associated with hedonic purchases: (1) perform altruistic behaviors (Khan and Dhar 2006; Lee-Wingate and Corfman 2010; Strahilevitz and Myers 1998), (2) expend effort (Kivetz and Simonson 2002; Kivetz and Zheng 2006), and (3) find deals (Khan and Dhar 2010; Zheng and Kivetz 2009) (e.g., sales promotions).

Performing altruistic behaviors can counterbalance the guilt associated with self-centric consumption and serve as justification for hedonic purchases. Khan and Dhar (2006) found that people who imagined engaging in an altruistic behavior prior to choosing between a necessity and a luxury were more likely to select the more luxurious option because they felt morally licensed to do so. In addition, Lee-Wingate and Corfman (2010) found that people can reduce the guilt evoked by consuming self-indulgent items by engaging in a kind behavior toward someone else (i.e. giving a promotional item to a friend rather than keeping it for themselves).

Another way that consumers can reduce guilt and justify hedonic consumption is through the expenditure of effort. People who have performed a difficult task may feel they have earned the right to engage in hedonic consumption as a reward for their hard work. Kivetz and Zheng (2006) found that higher effort and (bogus) positive feedback increased preference for vice versus virtue rewards because people felt entitled to them. Kivetz and Simonson (2002) investigated when consumers choose luxury over necessity rewards with frequency programs. They found that consumers were more likely to choose luxury over necessity rewards when the frequency program had high (versus low) program requirements, presumably because higher efforts reduced the guilt that is associated with hedonic consumption.

Finally, finding deals is an effective way to reduce guilt and increase hedonic consumption. Consumers may justify purchasing a desirable but unnecessary product by reasoning that they didn't pay full price. In support of this, Zheng and Kivetz (2009) showed that sales promotions enhance the purchase likelihood of hedonic products but have little impact on utilitarian ones. Using cross-category bundles containing both hedonic and utilitarian products, Khan and Dhar (2010) showed that a bundle discount increased purchase likelihood if the discount appeared to represent savings on the hedonic product but not on the utilitarian product.

These methods of guilt reduction - engaging in altruistic behavior, expending effort, and finding deals - may be effective but are not always practical given the limited resources of consumers and the negative consequences of continual promotions and discounts for companies. We propose that oddending pricing is a practical and effective way of decreasing guilt and increasing purchase likelihood when it comes to hedonic consumption.

\section{When and why odd-ending pricing is effective}

In line with previous research, we define odd-ending prices as prices that are a few cents (or one cent) below their roundending counterparts (Schindler 1991). For instance, an oddending price of $\$ 3.95$ or $\$ 3.99$ is just below the round-ending price of $\$ 4.00$. Odd-ending prices, though identical to their round-ending counterparts for all intents and purposes, have proven to be an effective strategy for increasing demand (Holdershaw et al. 1997; Kalyanam and Shively 1998; Manning and Sprott 2009; Schindler and Kibarian 1996; Stiving and Winer 1997). Much research has been dedicated to understanding why this is the case (see Appendix 1 for a summary of research in the area). Some researchers propose that buyers attend most to the extreme left digits of prices 
(ignoring or paying very little attention to the ending digits), so that \$3.99 appears substantially lower than $\$ 4.00$ (Manning and Sprott 2009; Thomas and Morwitz 2005; Stiving and Winer 1997). This "level effect" may be due to people's habit of reading multiple-digit numbers from left to right (Poltrock and Schwartz 1984), or by limitations in buyers' information processing capabilities or numerical cognition (Guéguen and Legoherel 2004; Schindler and Kibarian 1996; Thomas and Morwitz 2005).

There is also a large body of literature that supports the image or meaning mechanism for the effectiveness of oddending prices. According to this research, consumers infer meaning from the right-hand digits of prices, and oddending prices (such as those that end with 5 or 9) are heuristics that the product is low-priced or on sale. For example, Quigley and Notarantonio (1992) found that participants were more likely to say that a product with a 99-ending (versus 00ending) price is "probably on sale". Similarly, Schindler and Kibarian (1996) found that consumers are more likely to judge a 99-ending price to be lower and to represent a discount than a 00 -ending price. Other research has found that consumers considering an odd-ending price are under the impression that they are receiving a price discount, equal to an amount subtracted from the round-ending price (Schindler and Kirby 1997). Because they perceive the subtracted amount of an odd-ending price as an unexpected gain, an odd-ending pricing technique should significantly enhance the persuasiveness of gain-framed versus loss-framed messages (Choi et al. 2012) and signal a good deal to buyers.

Although the odd-ending pricing effect is fairly robust, there are situations in which it is weakened or even erased. For example, odd-ending pricing has a lower impact on price perception when the difference in the rightmost digit does not alter the leftmost digit (Thomas and Morwitz 2005). That is, $\$ 15.99$ (vs. \$16.00) is less effective than \$19.99 (vs. \$20.00) because the leftmost digit does not change from 2 to 1 in the first example. In addition, the effectiveness of odd-ending pricing has been found to be moderated by purchase goals. Manning and Sprott (2009) found that odd-ending pricing was most effective when the price level was higher (e.g. \$39.99 vs. \$3.99) and the shopping goal involved buying for an acquaintance. When prices were lower, or when the shopping goal involved buying for a friend, price-ending did not affect choice. These findings are especially relevant to the current research as they suggest that different consumption motives or aspects of the product can influence the effectiveness of odd-ending pricing. It is also possible that these results were obtained not because of differential attention to higher versus lower prices or importance of potential savings between product alternatives, as the authors theorize, but to the fact that some purchases need more justification than others, and oddending prices can be used for justification purposes.
Hypotheses

We extend previous research on the image effect of odd-ending pricing and suggest that buyers might use the perception that they are receiving a discount to justify certain types of purchases. As discussed earlier, considerable empirical evidence suggests that it is easier to spend money on "necessary" and practical utilitarian products than it is to spend money on "frivolous" and nonessential hedonic products. Perceptions of low-prices or discounts, however, can increase hedonic consumption by providing justification for such purchases (Khan and Dhar 2010). By combining theory about the discount image of odd-ending prices and the role of justification on hedonic purchases, we contend that oddending prices facilitate hedonic purchases by reducing the guilt associated with such purchases. That is, oddending prices should provide an opportunity to reduce guilt for people who are seeking justification for hedonic purchases, a tendency that we refer to as the oddpricing justification effect (OPJE). However, such subtle pricing differences should not make a difference in the purchase likelihood of utilitarian products, which are considered necessary purchases and do not arouse consumption guilt.

H1: Odd-ending vs. round-ending prices will increase the purchase likelihood of hedonic products by reducing anticipated consumption guilt but have no impact on the purchase likelihood or anticipated guilt of utilitarian products.

Furthermore, because a lack of monetary prudence is the prime cause of guilt in hedonic purchases (Prelec and Loewenstein 1998), it stands to reason that when guilt is not related to monetary decisions, odd-ending prices should not differentially influence purchase likelihood.

H2: Odd-ending vs. round-ending prices will increase the purchase likelihood of hedonic (but not utilitarian) products only when the anticipatory guilt is in the monetary domain.

Moreover, because most justifications take place at a low level of conscious awareness, making buyers aware of the trivial difference between odd- and round-ending prices should attenuate the magnitude of the OPJE.

H3: The effect of price-ending on purchase intention for hedonic products will be attenuated when consumers are made aware of the trivial difference between oddand round-ending prices. 
The OPJE is in line with previous research on the effectiveness of sales promotions or price discounts in that it reduces guilt and provides external justification for hedonic consumption. However, the use of sales promotions or price discounts leads to some concerns. First, frequent pricing discounts or promotions lead consumers to develop expectations about future marketing activity (Lattin and Bucklin 1989). Pricing promotions are effective when they are considered exceptions. However, if consumers come to expect these promotions and use discount prices as references for how much the product should cost, this might adversely affect product sales when standard prices, which tend to be higher than sales prices, are set. Hence, it becomes difficult for retailers to go back to using non-sale prices once the sales promotion has run its course, due to the lower price expectations of consumers. In addition, frequent sales or pricing promotions could impair brand-loyalty (Kalyanaram and Little 1994). If a consumer buys a product on promotion regularly, s(he) tends to attribute the purchase to the promotion rather than the perceived benefit from the brand. Thus, we expect odd-ending pricing to be an appealing alternative for companies selling hedonic products as it minimized the potential adverse effects of sales promotions and price discounts.

We systematically test our hypotheses in the studies below. In Study 1, we examine whether odd-ending prices influence consumer choice between hedonic and utilitarian options. In Study 2 we test the hypothesis that guilt-reduction mediates the relationship between pricing type and hedonic consumption. In Study 3, we manipulate different types of guilt to investigate whether odd-ending prices are effective at increasing purchase likelihood when anticipated guilt is in a domain other than financial. Finally, in Study 4, we explore a potential way of erasing the OPJE - by making consumers cognitively aware of the trivial difference between odd-ending and roundending prices.

\section{Study 1: the odd-ending pricing justification effect and choice behavior}

The objective of this study is to provide preliminary evidence for the OPJE in a choice context. Consumers often face situations in which they may choose between a hedonic and a utilitarian option. If the two options are presented separately, people are likely to evaluate the hedonic option more favorably than the utilitarian option. However, this effect is greatly attenuated when both options are presented together because it is harder to justify purchasing the hedonic product in that situation (Okada 2005). In Study 1, we test the OPJE in a choice context by investigating how odd-ending prices affect preferences for hedonic versus utilitarian options.

\section{Method}

The study had a single-factor (hedonic product price-ending: odd-ending [\$599], round-ending [\$600]) between-subjects design. Fifty-four students ( 29 men and 25 women, $M_{\text {age }}=$ 21.8 years) from a major Midwestern university participated in the study for course credit. For the choice task, we designed a scenario involving two laptop computers from different brands. The computers' functional features (HDD memory size, screen, system memory, and warranty) were identical. However, they differed in terms of weight (4.9 lb. vs. $5.8 \mathrm{lb}$.), visual attractiveness $(4.8 / 5.0$ vs. $3.2 / 5.0)$, and price $(\$ 599$ [\$600] vs. \$530). These varying attributes reflect Chitturi et al. (2008) finding that laptop weight and visual attractiveness represent hedonic attributes. To prevent confounding effects of prior knowledge of actual brands, we designated the two computer brands by the letters A and B. Brand A offered greater hedonic attributes and a higher price than Brand B (Appendix 2 provides additional details of the stimuli.)

Before conducting the main study, we ran a pretest to make sure Brand A (the hedonic option) is perceived to be less necessary than Brand B (the utilitarian option). In the pretest, 46 participants were recruited from Amazon's Mechanical Turk. We used a single-item nine-point scale to measure the comparable necessity of the two computers (i.e., I think buying Brand A compared to Brand B will be more necessary: very unlikely (1) very likely (9)). If participants feel that Brand A is less necessary of a purchase than Brand B, the mean rating should be less than 5 (i.e. significantly below the median of the scale). Indeed, a one sample t-test revealed that this was the case $(M=4.24 ; t(45)=-2.22, p=0.031)$, suggesting that our manipulation was successful. We now present the results of the main study.

Results

We predicted that people would be more likely to choose the hedonic option over the utilitarian option if it has an oddending price than a round-ending price. A chi-square test was performed to assess this prediction. Results revealed that $85 \%$ of participants chose the hedonic laptop over the utilitarian laptop when it was priced at $\$ 599$, but only $56 \%$ of participants chose the hedonic laptop when it was priced at $\$ 600$. A test of proportions revealed that the choice share of Brand A differed significantly across price conditions $\left(M_{\mathrm{odd}}=85 \%\right.$, $M_{\text {round }}=56 \%, z=2.3, p=0.02$ ), which supports H1.

In summary, consistent with the OPJE, more people chose the hedonic option over the utilitarian one when the hedonic option had an odd-ending price than when it had a round- 
ending price. Presumably, this is because odd-ending prices reduce the anticipated guilt consumers experience with hedonic consumption. We test this hypothesis directly in the next study.

\section{Study 2: influence of guilt reduction in the odd-ending pricing justification effect}

The primary objective of Study 2 is to investigate the underlying mechanism for the effectiveness of odd-ending pricing on hedonic consumption. People anticipate negative emotions such as guilt with hedonic, but not utilitarian, consumption. We hypothesize that the discount image associated with oddending prices diminishes these emotions and serves as justification for consumption, ultimately leading to greater purchase likelihood.

In addition, we attempt to replicate our findings from Study 1 for hedonic versus utilitarian motives rather than hedonic versus utilitarian products. Some products are generally considered hedonic or utilitarian in nature (e.g. chocolate versus detergent). However, as discussed previously, people may value different aspects of the same merchandise (Pham 1998), such that some consumers are motivated to buy SUVs for their design (hedonic motive), whereas others choose them for their safety (utilitarian motive). If our theorizing is correct, hedonic and utilitarian motives should affect guilt and purchase likelihood in the same way as hedonic and utilitarian products. Thus, we extend our research in the current study and investigate whether odd-ending pricing differentially affects purchase likelihood of the same product when hedonic versus utilitarian motives are elicited.

Method

One-hundred and five students (62 men and 43 women, $M_{\text {age }}=$ 21.3 years) from a major Midwestern university participated in a 2 (price-ending: odd-ending [\$99.95], round-ending [\$100.00]) $\times 2$ (motivation: utilitarian, hedonic) betweensubjects study for course credit. Participants were randomly assigned to the four conditions.

Participants in the hedonic and utilitarian motive groups read two different purchase scenarios. Those in the utilitarian motive condition were asked to imagine that they want to purchase new headphones because they are experiencing poor sound quality with their current headphones. Participants in the hedonic motive condition were asked to imagine that, although the headphones they currently own still have excellent sound quality, they want to buy new headphones because their current ones are quite old fashioned.

We ran a pretest $(N=56)$ to examine whether the manipulation scenarios actually contributed to the formation of different perceptions of necessity for the headphones. We used a similar measure from Study 1 to conduct this manipulation check (i.e., under the circumstances, I think buying these headphones will be: unnecessary (1) necessary (9)) but asked about each headphone separately since this study does not use a choice DV. Results showed that participants in the hedonic motive condition felt that their purchase would be relatively unnecessary, with a mean rating significantly below the scale median value of $5\left(M_{\text {hedonic }}=4.19, t(26)=\right.$ $-2.74, p=0.011)$. Participants in the utilitarian motive condition, however, reported that their purchase would be relatively necessary, as indicated by a mean rating significantly higher than $5\left(M_{\mathrm{utilitarian}}=5.97, t(28)=2.50\right.$, $p=0.018$ ).

After participants read and imagined their assigned motivation scenarios, we showed them an ad for a pair of Sennheiser HD 238 headphones, featuring a product picture and a list of product attributes, which included the price (oddending: \$99.95; round-ending: \$100.00). We chose these prices not just because of their endings but because they reflect real-world retail prices for the headphones (Amazon.com priced the product at $\$ 99.95$, Apple Store at $\$ 100.00$, at the time this study was run).

Feelings of guilt were measured using a scale from Lee-Wingate and Corfman's (2010) study (i.e., "How guilty/regretful/uneasy/hesitant/reluctant/sorry would you feel about spending money on purchasing the product?"; not at all (1) to extremely (7); $\alpha=0.94)$. Likelihood of purchasing the headphones was measured using threeitems on nine-point scales ("Under the circumstances, the chance of you purchasing the headphones is very unlikely/very likely, very improbable/very probable, very possible/very impossible (r)" with (r) indicating reverse coding; $\alpha=0.80$ ). We also included brand familiarity (one-item, five-point scale, from not at all familiar (1) to very familiar (5)) as a potential covariate because previous research suggests brand familiarity may influence purchase likelihood (Ajzen et al. 1996; Anderson and Jolson 1980; Moorman et al. 2004). Finally, participants completed demographic questions and were dismissed from the study.

\section{Results and discussion}

Brand familiarity was not correlated with the independent variables but did correlate with the dependent variables. Thus, following Keppel (1982), we included brand familiarity as a covariate in the subsequent analyses. We used a two-way analysis of covariance (ANCOVA), with price-ending (oddvs. round-ending) and consumption motive (utilitarian vs. hedonic) as predictors. 
Feelings of guilt As predicted, there was a significant interaction between price-ending and motivation on feelings of guilt $(F(1,100)=5.14, p<0.05)$. Pairwise comparisons showed that an odd-ending price, compared with a roundending price, significantly reduced guilt when participants had a hedonic motive to purchase the headphones $\left(M_{\text {odd }}=\right.$ $\left.3.78, M_{\text {round }}=5.03, F(1,100)=10.66, p<0.01\right)$. When participants had a utilitarian motive to purchase the headphones, there was no difference in feelings of guilt between the two price-ending conditions $\left(M_{\text {odd }}=3.95, M_{\text {round }}=3.97, F(1\right.$, $100)=0.002, p>0.96$ ) (see Fig. 1 top). Thus, when participants had a hedonic consumption motive, they felt less guilty about purchasing a product with an odd-ending price (vs. a roundending price). However, price-ending had no impact on participants' feelings of guilt when they had a utilitarian consumption motive. It's relevant to note that odd-ending pricing not only decreased anticipated guilt for hedonically motivated consumers, it dropped ratings to below the mid-point of the scale, bringing them to levels similar to those in the utilitarian motivation condition.

There was a marginal effect of brand familiarity on feelings of guilt $(F(1,100)=2.77, p<0.1)$. As consumers become familiar with a brand, they feel more confident in their decisions (Laroche et al. 1996) and perceive less risk of consumption (Dunn et al. 1986), which can lower feelings of anticipated guilt (Chakraborty et al. 1997).
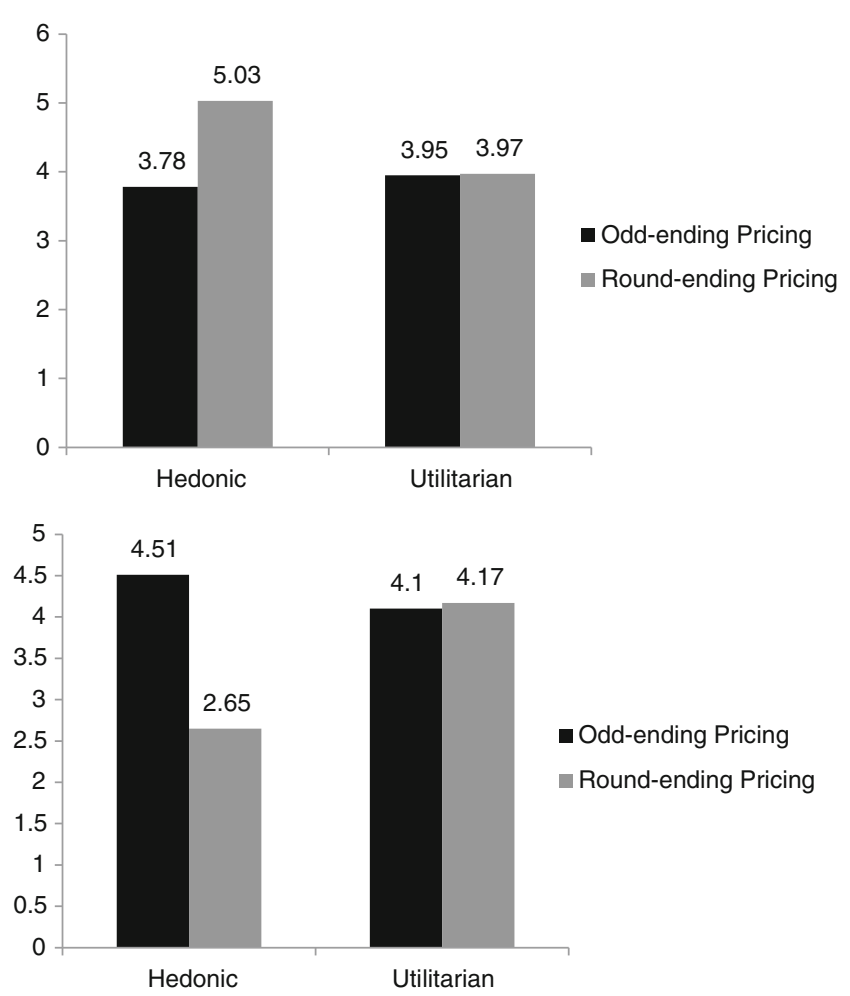

Fig. 1 Interaction effect of price-ending and consumption motivation on feelings of guilt (top) and purchase likelihood (bottom) in Study 2
Purchase likelihood There was a significant two-way interaction between price-ending and consumption motive on purchase likelihood $(F(1,100)=9.70, p<0.01)$. Pairwise comparisons showed that an odd-ending price had a greater impact on purchase likelihood than a round-ending price for participants in the hedonic motive condition $\left(M_{\mathrm{odd}}=4.51, M_{\mathrm{round}}=2.65\right.$, $F(1,100)=18.36, p<0.001)$, but there was no price-ending difference on purchase likelihood for participants in the utilitarian motive condition $\left(M_{\text {odd }}=4.10, M_{\text {round }}=4.17, F(1,100)=\right.$ 0.02) (see Fig. 1 bottom). In other words, people with hedonic (but not utilitarian) motives were more likely to purchase the headphones when the price is odd-ending rather than roundending, a finding that provides further support for H1. Brand familiarity also had a significant impact on purchase likelihood $(F(1,100)=7.97, p<0.01)$.

Moderated mediation We hypothesized that feelings of guilt would mediate the OPJE, which in turn should be moderated by differences in motives. Using Preacher et al. (2007) method, we conducted a moderated mediation test and found that guilt mediated the effect of odd-ending pricing on purchase likelihood if participants had a hedonic motive (indirect effect; $z=2.97, p<0.01)$, but not when they had a utilitarian one $(z=$ $0.04)$.

\section{Study 3: a boundary effect for the OPJE: domain of guilt}

The objective of this study is to further examine the role of guilt in influencing the purchase likelihood of hedonic products and to explore a boundary effect for the impact of odd-ending pricing on hedonic consumption. People experience guilt in many domains, such as health-related guilt if they indulge in a high-calorie dessert. However, odd-ending prices shouldn't reduce guilt or increase consumption in contexts where saving money is irrelevant to the concern at hand. That is, guilt type and justification type need to be domain matched in order for the OPJE to work (saving money shouldn't assuage guilt from eating unhealthy food, but working out or engaging in other healthful activities might). The OPJE reduces guilt and increases purchase likelihood when people are concerned about money because of the discount perception created by an odd-ending price. However odd-ending pricing should not be effective at reducing guilt and increasing purchase likelihood when people are concerned about their health rather than their finances. Study 3 tests this hypothesis.

Method

One-hundred college students $\left(57\right.$ men, 43 women, $M_{\text {age }}=$ 21.2 years) at a large Midwestern university participated in 
the study for course credit. The study had a 2 (price-ending: odd-ending [\$5.95], round-ending [\$6.00]) $\times 2$ (concern: health, money) between-subjects design. Participants were randomly assigned to each condition and completed the study on computers. Two scenarios were used to elicit money- and health-related concerns. The health concern scenario read: "Imagine that you are at a restaurant downtown with your friend and are having dinner. You remember that at a recent regular health checkup, your doctor cautioned you about your health because you had gained weight. At the restaurant, you are given a dessert menu that features several attractive dishes." The money concern scenario read: "Imagine that you are at a restaurant downtown with your friend and are having dinner. You remember that your income has been significantly reduced since you changed jobs. At the restaurant, you are given a dessert menu that features several attractive dishes." Participants then proceeded to another screen that showed appealing pictures of cakes (indulgent desserts such as chocolate and cake are considered hedonic in nature (Mishra and Mishra 2011; Strahilevitz and Myers 1998)). The cakes were priced at $\$ 5.95$ or $\$ 6.00$ depending on the condition. We measured feelings of guilt ("How guilty/regretful/uneasy/hesitant/reluctant/sorry would you feel about ordering a dessert?"; not at all (1) to extremely (7); $\alpha=0.94)$ and likelihood of ordering a dessert (Under the circumstances, the chance of you purchasing a dessert is very unlikely/very likely, very improbable/very probable, very possible/very impossible (r)" with (r) indicating reverse coding; $\alpha=0.93$ ) using the same scales from studies 2 and 3. At the end of the study, participants provided demographic information and were dismissed.

\section{Results and discussion}

Feelings of guilt An analysis of variance (ANOVA) with concern type and price-ending as predictors and feelings of guilt as the dependent variable revealed a significant interaction effect $(F(1,96)=4.20, p<0.05)$. Pairwise comparisons showed that an odd- compared with a round-ending price significantly reduced feelings of guilt when participants were concerned about money $\left(M_{\text {odd }}=3.76, M_{\text {round }}=4.81\right.$, $F(1,96)=5.28, p<0.05)$ but not when they were concerned about health $\left(M_{\text {odd }}=5.02, M_{\text {round }}=4.75, F(1,96)=\right.$ $0.36, p>0.55$ ) (see Fig. 2 top).

Purchase likelihood Another ANOVA with the same predictors but purchase likelihood as the dependent variable revealed a marginally significant interaction effect of concern type and price-ending $(F(1,96)=3.66, p<0.06)$. Pairwise comparisons showed that an odd-ending price, compared with a round-ending price, increased purchase likelihood significantly when participants were concerned
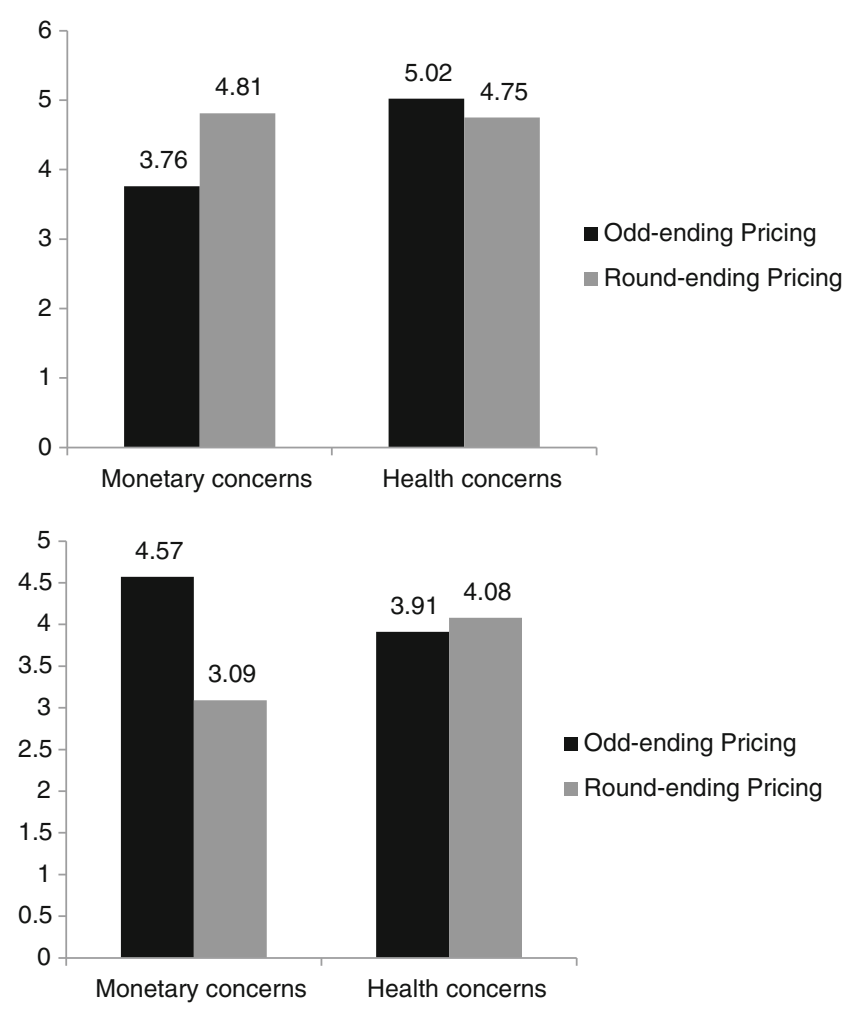

Fig. 2 Interaction effect of price-ending and concern type on feelings of guilt (top) and purchase likelihood (bottom) in Study 3

about money $\left(M_{\text {odd }}=4.57, M_{\text {round }}=3.09, F(1,96)=5.87\right.$, $p<0.05)$, but it not when they were concerned about health $\left(M_{\text {odd }}=3.91, M_{\text {round }}=4.08, F(1,96)=0.08\right.$, $p>0.77$ ) (see Fig. 2 bottom).

Moderated mediation To test our prediction of moderated mediation of the OPJE by concern type, we conducted a moderated mediation analysis using Preacher et al. (2007) method. The results of this test revealed that guilt mediated the effect of price-ending on purchase likelihood when participants were concerned about money (indirect effect; $z=2.13, p<0.05$ ), but not when they were concerned about health $(z=-0.59, p>0.55)$.

In sum, guilt diminished, and purchase likelihood increased, through the use of odd-ending prices when anticipated guilt was money related. As expected, however, similar results were not found when anticipated guilt was health related. These results provide support for $\mathrm{H} 2$.

\section{Study 4: cognitive awareness of price differences and the OPJE}

In Study 4, we investigate whether the OPJE can be erased, a question that may be important from a public 
policy perspective. Previous research shows that awareness of an unwanted influence often leads people to try to correct their initial biased judgments (Wilson and Brekke 1994). Asking questions can prompt such judgment correction by shifting attention from automatic to more deliberate cognitive processing. Fitzsimons and Williams (2000) show that asking questions can mitigate consumer decision bias by changing their behavior through a conscious elaboration mechanism. Asking questions also offers people a break from decisionmaking and orients them toward rational thinking, instead of automatic reactions to stimuli. Because the OPJE depends on the perception of odd-ending prices as a discount, we posit that correcting this perception by asking questions that make consumers think about whether odd-ending prices are significantly different from their round-ending counterparts will attenuate the OPJE.

\section{Method}

Three-hundred and twenty-nine participants (183 men and 146 women, $M_{a g e}=32.3$ years) were recruited from Amazon's Mechanical Turk. The study had a 2 (price-ending: odd-ending [\$99.95], round-ending [\$100.00]) $\times 2$ (motivation: hedonic, utilitarian $) \times 2$ (timing of elicitation: before, after) between subjects design. Participants were randomly assigned to one of the eight conditions.

A procedure similar to that from Study 2 was used. That is, participants were randomly assigned to a hedonic or utilitarian motivation condition and asked to rate how likely they would be to purchase a new pair of headphones (Sennheiser HD-280 PRO). However, the current study differs from the previous one with the addition of two questions aimed to direct participants' attention to the insignificant difference between oddending and round-ending prices. Depending on which condition participants were in, they answered the questions "How different is $\$ 99.95$ from $\$ 100.00$ ?" and "If the price was $\$ 100.00$ (\$99.95), how much would it affect your purchase decision?" on a scale from (1)= not at all to (9)=extremely, either before or after the purchase likelihood $\mathrm{DV}^{1}$.

Purchase likelihood was measured using the same scale from Study 2 ("under the circumstances, the chance of you purchasing the headphones is very unlikely/very likely, very improbable/very probable,

\footnotetext{
${ }^{1}$ We found similar results regardless of whether the items were presented before or after the DV (Before: $M_{\text {different }}=1.85, S D=1.28 ; M_{\text {affect }}=3.23$, $S D=2.52$; After: $M_{\text {different }}=1.63, S D=1.36 ; M_{\text {affect }}=3.20, S D=2.95$ ).
}

very possible/very impossible (r)" with (r) indicating reverse coding; $\alpha=0.93$ ). Also, because a real product was presented, we measured brand familiarity so it could be used as a covariate in the analyses. At the end of the study, participants completed demographic questions and were dismissed.

\section{Results and discussion}

A 2 (price-ending: odd-ending [\$99.95], round-ending [ $\$ 100.00]) \times 2$ (motivation: hedonic, utilitarian) $\times 2$ (timing of elicitation: before, after) ANCOVA revealed a main effect of motivation type on purchase likelihood; participants in the utilitarian motivation condition reported greater purchase likelihood than those in the hedonic motivation condition $(F(1,320)=6.32, p=0.012)$. The impact of pricing type was not significant as a main effect, though the trend was for purchase likelihood to be greater in the odd- rather than round- ending pricing condition $(F(1,320)=2.46, p>0.11)$. The main effect of elicitation timing on purchase likelihood was not significant $(F(1,320)<1, p>0.94)$, but brand familiarity had a strong effect on purchase likelihood $(F(1,320)=24.22$, $p<0.001)$.

More central to our hypothesis, there was a significant three-way interaction between price-ending, motivation, and timing of elicitation on purchase likelihood, $(F(1$, $320)=4.34, p=0.038$ ). Decomposing this interaction reveals no interaction between price-ending and motivation type for participants who were made aware of the trivial pricing difference before responding to the purchase likelihood question $F(1,320)=1.25, p>0.26$. However, a marginally significant 2 -way interaction was found for participants who were not aware of the pricing difference beforehand, $F(1,320)=3.60, p<0.06$.

Consistent with our previous findings, price-ending influenced purchase likelihood for those in the hedonic motivation condition $\left(M_{\mathrm{odd}}=4.51, M_{\text {round }}=3.19, F(1\right.$, $320)=6.58, p=0.011)$, but not in the utilitarian motivation condition $\left(M_{\text {odd }}=4.55, M_{\text {round }}=4.54, F(1,320)<\right.$ $1, p>0.98$ ), when the timing of elicitation was after the DV. Making people aware of the trivial difference between odd-ending and round-ending prices before they report purchase likelihood, however, erased the OPJE. That is, purchase likelihood did not vary as a function of price-ending for participants in the hedonic motivation condition $\left(M_{\mathrm{odd}}=3.76, M_{\text {round }}=4.03, F(1\right.$, $320)<1, p>0.59$ ) or the utilitarian motivation condition $\left(M_{\text {odd }}=4.73, M_{\text {round }}=4.21, F(1,320)=1.05, p>0.30\right)$ when the timing of elicitation was before the DV.

In summary, the OPJE works only if consumers are not consciously made aware of the trivial difference between odd-ending prices and their round-ending 
counterparts. Replicating results from the previous studies, odd-ending (versus round-ending) prices increased the purchase likelihood of hedonic products when consumers are not made aware of the trivial difference between the pricing types. However, consumers who actively considered how little difference there is between the two price endings before revealing their purchase intention were no more likely to purchase hedonic products that have odd-ending prices than round-ending prices. These results suggest the OPJE operates on an unconscious level, and simply making salient the trivial difference between odd-ending and round-ending prices erases the effect. Consumers who wish to minimize the unconscious influence of marketing on their purchase behaviors may opt to think more critically about the potential psychological impact of price-ending before making decisions.

\section{General discussion}

In the current research, we explored the idea that the discount image of odd-ending prices assuages the anticipated guilt of hedonic consumption, which leads to greater purchase likelihood. When guilt is already alleviated by other external or internal justifications, this odd-ending price justification effect (OPJE) disappears. The impact of an odd-ending price is meaningful only if consumers need to ease monetary guilt induced by hedonic purchases. If guilt relates not to money concerns but to health concerns, odd-ending prices do not affect guilt or purchase decisions. In addition, the OPJE appears to operate at an unconscious level, as making consumers aware of the trivial difference between an odd-ending price and its round-ending counterpart erases the effect.

We tested our hypotheses in four studies. Study 1 supported our primary assertion that odd-ending pricing increases purchase likelihood for hedonic products. Study 2 built upon these findings by showing that this effect is mediated by a reduction in consumers' anticipated guilt. In addition, Study 2 supported our hypothesis that not all types of consumption is affected by odd-ending pricing utilitarian consumption does not elicit anticipated guilt and therefore is not influenced by price-ending. Study 3 tested and found support for a boundary condition for the effect of odd-ending prices on hedonic consumption. That is, odd-ending prices assuage guilt and increase purchase likelihood only when the guilt is related to monetary, not to nonmonetary, concerns. Finally, Study 4 investigated a theoretically driven method of erasing the OPJE - since the effectiveness of odd-ending pricing relies on its discount perception, making consumers aware of the negligible difference between odd- and round- ending prices should, and does, erase the OPJE. Together, these findings paint a powerful picture of how and why price ending affects hedonic and utilitarian consumption.

\section{Theoretical and managerial implications}

The current research shows that price-ending effects are not merely cognitive; they also have affective and motivational underpinnings. The results thus highlight the role of price endings on hedonic (vs. utilitarian) purchases, and offer alternative explanations for some previous findings. For example, Manning and Sprott (2009) observe that odd-ending (vs. round-ending) prices affect choice when the price level is higher and the shopping goal involves purchases for an acquaintance, but have little impact when the price level is lower and the shopping goal involves purchases for a friend. We posit that this effect exists because the latter purchase condition is a highly justifiable situation while the former situation is less justifiable and thus more guilt inducing. In other words, buying a low-priced gift for a friend is a justifiable expense and the perception of a discount is not needed to make a guilt-free purchase. It's harder to rationalize purchasing an expensive item for an acquaintance; thus the discount perception of odd-ending prices is needed to provide justification for the purchase.

Mishra and Mishra (2011) found that consumers prefer a price discount to a bonus pack for indulgent foods like chocolate because the price discount can reduce the guilt associated with consuming indulgent foods. However, the study did not provide a clear distinction between the type of guilt resulting from consumption of unhealthy foods (guilt stemming from health concerns) and spending money (guilt stemming from money concerns). Our results suggest that the OPJE should work differently depending on guilt type. Thus, when consumers are concerned about monetary expenditure, odd-ending prices reduce anticipated consumption guilt, leading to an increase in purchase. On the other hand, when consumers have health concerns related to being overweight, calorie count value expressed in an oddending number (e.g. 399 vs. 400 calories) may reduce guilt and increase the likelihood of consumption. This issue of "guilt and justification fit" needs further investigation.

Our findings may have implications for consumer welfare as well. Although pricing techniques to promote hedonic consumption can be effective, they also can be damaging to long-term consumer welfare. Indulgent consumption, such as binge drinking, overeating, and other 
extreme behaviors, is not only detrimental to consumers' physical health but also correlates negatively with financial health (Baumeister 2002). When consumers can justify such indulgent consumption, they are more likely to engage in these harmful behaviors (Kivetz and Simonson 2002). However, our results suggest that making consumers aware of the OPJE may erase its effect. From a public policy perspective, we therefore suggest a potential remedy in the form of consumer awareness campaigns that can counter the influence of odd-ending prices on discretionary spending. In the face of burgeoning consumer debt and self-control-related issues, our findings can help delineate consumer education programs that might enhance consumer welfare (Soman and Cheema 2011).

\section{Limitations and suggestions for future research}

It is important to note that we do not claim that OPJE will never work for utilitarian products, but that the perceived discount image of odd-ending prices provides an additional justification for the purchase of hedonic products. Previous research seems to show that oddending pricing affects demand for both hedonic and utilitarian products (e.g., Thomas and Morwitz's (2005) ballpoint pen; Gendall et al. (1997) a block of cheese, a frozen chicken, a hair dryer, etc.). However, it is difficult to classify these items as primarily hedonic or utilitarian simply based on product category. For example, Thomas and Morwitz (2005) used ballpoint pens as stimuli. A common ballpoint pen that can be bought at a large chain store for less than a dollar is likely to be considered a utilitarian product. However, it is difficult to conclude that the pens Thomas and Morwitz (2005) used are obviously utilitarian in nature when taking into consideration the description of the pen: "Avalon ballpoint pen, black-laser engraved, solid brass cap and barrel, state-of-the-art laser-engraved logo, twist action mechanism, ink color: black" (p. 57). In addition, unrevealed pictures, colors, design, shape, and other features of the pens could contribute to a different overall perception of the product. Furthermore, a product ostensibly categorized as utilitarian could be perceived as hedonic because of its price and brand. For example, Gendall et al. (1997) used the following product stimuli: a block of cheese $(\$ 5.00)$, a frozen chicken $(\$ 6.00)$, a box of chocolates $(\$ 10)$, a hair dryer $(\$ 20)$, an electronic kettle (\$50), and a blender (\$100). Although some of the products may seem to be utilitarian based on their functionality, they may very well have hedonic aspects because of price connotations. In any case, because the odd-pricing effect works in various different ways (price truncation, memory limitations, or left-to-right digit processing etc.), any or all of these could result in an increased demand for utilitarian products as well.

In the current research, we focused on the effect of psychological pricing on consumer preferences; future research could address how price-endings affect other behaviors. For example, Strahilevitz and Myers (1998) found that bundling a hedonic product with a promised donation to charity is more effective than bundling the donation with a utilitarian product, presumably because the promise of a donation reduces the guilt associated with hedonic consumption. If the guilt related to hedonic purchases has already been reduced by odd-ending prices, this pricing technique could affect charitable behavior. Thus a potential future research question could be whether purchases with odd-ending (vs. roundending) prices undermine altruistic behaviors.

Future research also could address how individual differences affect the odd-ending pricing effect. 2People who process information globally or holistically, rather than locally or analytically, tend to perceive figures on the basis of their global structure rather than local structure (Navon 1977). We expect the discount image of odd-ending prices to be strongest when an individual engages in global or holistic processing due to a focus on the overall impression of the price. Therefore, another future research question could be whether information processing style moderates the impact of odd-ending prices when consumers need to justify their purchases. Relatedly, previous research shows that positive mood leads people to engage in more global processing, whereas negative mood induces local processing (Basso et al. 1996). Thus, mood might be another variable that influences the impact of oddending pricing.

Another dispositional difference that could be considered in this area of research is regulatory focus. Promotion-focused individuals tend to focus on speed in conducting a task and try to maximize their gains, whereas prevention-focused individuals focus on accuracy in order to minimize losses (Higgins 1997). Those who are promotion-oriented are expected to be more motivated to justify their purchases, and may be more susceptible to the discount image of odd-ending prices than prevention-oriented individuals.

Finally, prior research (Schindler and Kibarian 2001; Schindler and Kirby 1997) has proposed an associationbased model to explain the effectiveness of odd-ending prices. According to this perspective, such prices are more readily associated with sales promotions, discounts, and other incentives. We developed our hypotheses using the discounted image explanation; additional research could examine the nature of these various mental representations in greater detail to further clarify the processes underlying the effects of oddending prices. 


\section{Appendix 1}

Table 1 Summary of research on odd-ending pricing

Paper Finding Process

Schindler and Wiman 1989

Schindler 1991

Quigley and Notarantonio 1992

Schindler and Kibarian 1996

Stiving and Winer 1997

Schindler and Kirby 1997

Gendall et al. 1997

Holdershaw et al. 1997

Kalyanam and Shively (1998)

Estelami 1999

Gedenk and Sattler 1999

Schindler and Kibarian 2001

Coulter 2001

Guéguen and Legoherel 2004

Bizer and Schindler 2005

Thomas and Morwitz 2005

Liang and Kanetkar 2006

Schindler 2006

Harris and Bray 2007

Fortin et al. 2008

Manning and Sprott 2009

Kleinsasser and Wagner 2011

Mace 2012

Choi et al. 2012
Odd-ending prices recalled less accurately than even-ending prices

Review of the symbolic meaning of odd-price endings

Odd-ending price effect attributed to the notion that a product is on sale

Retail prices ending with 99 found to increase consumer purchase likelihood in a retail clothing outlet.

Empirical analysis of scanner data found price endings affect consumer purchases.

Overrepresentation of prices ending with 0,5 , and 9 found in retail advertising.

Field study supported the efficacy of odd-ending pricing.

Content analysis of 840 advertisements that found that $90 \%$ of advertised prices ended with the digit 9 or 5

Odd-ending prices led to a $12 \%-76 \%$ increase in sales.

Odd price endings made computations more difficult for consumers in multi-dimensional price advertisements.

Odd-ending pricing strategy recommended for retailers' adoption unless strong price-quality image effects exist.

Odd-ending pricing increased the likelihood of consumer judgment that an advertised price was low and discount-driven.

Demand for brands with odd- versus even-price ending depended on the order in which the digits were exposed to the consumer.

Perceived rate of discount was higher when an odd-ending (vs. even-ending) price followed a zero-ending initial price.

Consumers dropped off the rightmost two digits such that they showed greater purchase likelihood for products with odd-ending pricing.

Odd-ending pricing was more effective when the left-most digits differ.

Consumers processed price information at a digit by digit level and not at a holistic level.

Odd-ending prices, specifically, 99-ending price signaled low price to consumers.

Women were more likely to respond favorably to odd-ending pricing than men.

While consumers responded favorably to 99-ending prices in general, price differences were not salient when the retailer was perceived to be of high quality.

Just-below pricing shifted choice share in favor of the lower-priced alternatives.

High, but not low, involvement led to consumer preference for products whose price ended with 9 .

Odd-ending prices selectively enhanced sales for small brands belonging to weaker categories, and lost their effectiveness as odd-ending pricing practices intensified.

Gain-framed messages (vs. loss-framed messages) were more effective when combined with odd-ending pricing.
None proposed.

Supports image effects.

Supports image effects.

None proposed.

Supports both level effects and image effects.

Supports level effects.

None proposed.

None proposed.

None proposed.

None proposed.

None proposed.

Supports image effects.

Supports level effects.

Supports level effects.

Supports level effects.

Supports level effects.

Supports level effects.

Supports image effects.

Supports image effects.

Supports image effects.

None proposed.

Supports image effects.

Supports both level and image effects.

Supports image effects. 


\section{Appendix 2}

Table 2 Details of the stimuli used in Study 1

\begin{tabular}{|c|c|c|}
\hline Features & Brand A & Brand B \\
\hline Processor & Intel Corei3 Processor & Intel Corei3 Processor \\
\hline HDD memory size & $500 \mathrm{~GB}$ & $500 \mathrm{~GB}$ \\
\hline Screen & 15.6" HD (720p) LED & 15.6" HD (720p) LED \\
\hline System memory & $4 \mathrm{~GB}$ & 4 GB \\
\hline Weight & $4.9 \mathrm{lb}$ & $5.8 \mathrm{lb}$ \\
\hline Warranty & 1 year limited & 1 year limited \\
\hline Visual attractiveness $\mathrm{s}^{\mathrm{a}} /$ optional color & 4.8/5.0 (black and white) & 3.2/5.0 (black only) \\
\hline
\end{tabular}

a 1: Unattractive 5: Very attractive

\section{References}

Ajzen, I., Brown, T. C., \& Rosenthal, L. H. (1996). Information bias in contingent valuation: effects of personal relevance, quality of information, and motivational orientation. Journal of Environmental Economics and Management, 30, 43-57.

Anderson, R. E., \& Jolson, M. A. (1980). Technical wording in advertising: implications for market segmentation. Journal of Marketing, 44(1), 57-66.

Basso, M. R., Schefft, B. K., Ris, M. D., \& Dember, W. N. (1996). Mood and global-local visual processing. Journal of the International Neuropsychological Society, 2(3), 249-255.

Batra, R., \& Ahtola, O. T. (1991). Measuring the hedonic and utilitarian sources of consumer attitudes. Marketing Letters, 2(2), 159-170.

Baumeister, R. F. (2002). Yielding to temptation: self-control failure, impulsive purchasing, and consumer behavior. Journal of Consumer Research, 28(4), 670-676.

Bizer, G. Y., \& Schindler, R. M. (2005). Direct evidence of ending-digit drop-off in price information processing. Psychology \& Marketing, 22(10), 771-783.

Chakraborty, G., Allred, A., Sukhdial, A. S., \& Bristol, T. (1997). Use of negative cues to reduce demand for counterfeit products. In $\mathrm{M}$. Brucks \& D. J. MacInnis (Eds.), Advances in consumer research (pp. 345-349). Provo: Association for Consumer Research.
Chitturi, R., Raghunathan, R., \& Mahajan, V. (2008). Delight by design: the role of hedonic versus utilitarian benefits. Journal of Marketing, $72(3), 48-63$.

Choi, J., Lee, K., \& Ji, Y. (2012). What type of framing message is more appropriate with nine-ending pricing? Marketing Letters, 23(3), 603-614.

Coulter, K. S. (2001). Odd-ending price underestimation: an experimental examination of left-to-right processing effects. Journal of Product \& Brand Management, 10(5), 276-292.

Crowley, A. E., Spangenberg, E. R., \& Hughes, K. R. (1992). Measuring the hedonic and utilitarian dimensions of attitudes toward product categories. Marketing Letters, 3(3), 239-249.

Dunn, M. G., Murphy, P. E., \& Skelly, G. U. (1986). Research note: the influence of perceived risk on brand preference for supermarket products. Journal of Retailing, 62(2), 204-217.

Estelami, H. (1999). The computational effect of price endings in multidimensional price advertising. Journal of Product \& Brand Management, 8(3), 244-256.

Fitzsimons, G. J., \& Williams, P. (2000). Asking questions can change choice behavior: does it do so automatically or effortfully? Journal of Experimental Psychology: Applied, 6(3), 195-206.

Fortin, D., Cleland, S., \& Jenkins, A. (2008). Effects of advertised pricing on brand image for an on-line retailer. Proceedings of the 2008 Conference of the American Academy of Advertising, 263-275. 
Gendall, P., Holdershaw, J., \& Garland, R. (1997). The effect of odd pricing on demand. European Journal of Marketing, 31(11/12), 799-813.

Gedenk, K., \& Sattler, H. (1999). The impact of price thresholds on profit contribution-should retailers set 9-ending prices? Journal of Retailing, 75(1), 33-57.

Guéguen, N., \& Legoherel, P. (2004). Numerical encoding and oddending prices: the effect of a contrast in discount perception. European Journal of Marketing, 38(1/2), 194-208.

Harris, C., \& Bray, J. (2007). Price endings and consumer segmentation. Journal of Product \& Brand Management, 16(3), 200-205.

Higgins, E. T. (1997). Beyond pleasure and pain. American Psychologist, 52(12), 1280.

Hirschman, E. C., \& Holbrook, M. B. (1982). Hedonic consumption: emerging concepts, methods, and proposition. Journal of Marketing, 46(3), 92-101.

Holdershaw, J., Gendall, P., \& Garland, R. (1997). The widespread use of odd pricing in the retail sector. Marketing Bulletin, 8, 53-58.

Kalyanaram, G., \& Little, J. D. C. (1994). An empirical analysis of latitude of price acceptance in consumer package goods. Journal of Consumer Research, 21(3), 408-418.

Kalyanam, K., \& Shively, T. S. (1998). Estimating irregular pricing effects: a stochastic spline regression approach. Journal of Marketing Research, 35(1), 16-29.

Keppel, G. (1982). Design and analysis: A Researcher's Handbook(2nd ed.). Englewood Cliffs: Prentice-Hall.

Khan, U., \& Dhar, R. (2006). Licensing effect in consumer choice. Journal of Marketing Research, 43(2), 259-266.

Khan, U., \& Dhar, R. (2010). Price framing effects on purchase of hedonic and utilitarian bundles. Journal of Marketing Research, 47(6), 1090-1099.

Kivetz, R., \& Simonson, I. (2002). Earning the right to indulge: effort as a determinant of customer preferences toward frequency program rewards. Journal of Marketing Research, 39(2), 155-170.

Kivetz, R., \& Zheng, Y. (2006). Determinants of justification and self-control. Journal of Experimental Psychology: General, 135(4), 572-587.

Kleinsasser, S., \& Wagner, U. (2011). Price endings and tourism consumers' price perceptions. Journal of Retailing and Consumer Services, 18(1), 58-63.

Laroche, M., Kim, C., \& Zhou, L. (1996). Brand familiarity and confidence as determinants of purchase intention: an empirical test in a multiple brand context. Journal of Business Research, 37, 115-120.

Lattin, J. M., \& Bucklin, R. E. (1989). Reference effects of price and promotion on brand choice behavior. Journal of Marketing Research, 26(3), 299-310.

Lee-Wingate, S. N., \& Corfman, K. P. (2010). A little something for me and maybe for you, too: promotions that relieve guilt. Marketing Letters, 21(4), 385-395.

Liang, J., \& Kanetkar, V. (2006). Price endings: magic and math. Journal of Product \& Brand Management, 15(6), 377-385.

Macé, S. (2012). The impact and determinants of nine-ending pricing in grocery retailing. Journal of Retailing, 88(1), 115-130.

Manning, K. C., \& Sprott, D. E. (2009). Price endings, left-digit effects, and choice. Journal of Consumer Research, 36(2), 328-335.

Mishra, A., \& Mishra, H. (2011). The influence of price discount versus bonus pack on the preference for virtue and vice foods. Journal of Marketing Research, 48(1), 196-206.

Moorman, C., Diehl, K., Brinberg, D., \& Kidwell, B. (2004). Subjective knowledge, search locations, and consumer choice. Journal of Consumer Research, 31(3), 673-680.
Navon, D. (1977). Forest before trees: the precedence of global features in visual perception. Cognitive Psychology, 9(3), 353-383.

O'Curry, S., \& Strahilevitz, M. (2001). Probability and mode of acquisition effects on choices between hedonic and utilitarian options. Marketing Letters, 12(1), 37-49.

Okada, E. M. (2005). Justification effects on consumer choice of hedonic and utilitarian goods. Journal of Marketing Research, 42(1), 45-53.

Pham, M. T. (1998). Representativeness, relevance, and the use of feelings in decision making. Journal of Consumer Research, 25, 144 159.

Poltrock, S. E., \& Schwartz, D. R. (1984). Comparative judgments of multidigit numbers. Journal of Experimental Psychology: Learning, Memory, and Cognition, 10(1), 32-45.

Preacher, K. J., Rucker, D. D., \& Hayes, A. F. (2007). Addressing moderated mediation hypothesis: theory, methods, and prescriptions. Multivariate Behavioral Research, 42(1), 185-227.

Prelec, D., \& Loewenstein, G. (1998). The red and the black: mental accounting of savings and debt. Marketing Science, 17(1), 4-28.

Quigley, C. J., Jr., \& Notarantonio, E. M. (1992). An exploratory investigation of perceptions of odd and even pricing. Developments in Marketing Science, 15, 306-309.

Schindler, R. M. (1991). Symbolic meanings of a price ending. In R. H. Holman \& M. R. Solomon (Eds.), Advances in consumer research (Vol. 18, pp. 794-801). Provo: Association for Consumer Research.

Schindler, R. M. (2006). The 99 price ending as a signal of a low-price appeal. Journal of Retailing, 82(1), 71-77.

Schindler, R. M., \& Kibarian, T. M. (1996). Increased consumer sales response though use of 99-ending prices. Journal of Retailing, 72(2), 187-199.

Schindler, R. M., \& Kibarian, T. M. (2001). Image communicated by the use of 99 endings in advertised prices. Journal of Advertising, 30(4), 95-99.

Schindler, R. M., \& Kirby, P. N. (1997). Patterns of rightmost digits used in advertised prices: implications for nine-ending effects. Journal of Consumer Research, 24(2), 192-201.

Schindler, R. M., \& Wiman, A. R. (1989). Effects of odd pricing on price recall. Journal of Business Research, 19(3), 165-177.

Soman, D., \& Cheema, A. (2011). Earmarking and partitioning: increasing saving by low-income households. Journal of Marketing Research, 48, 14-22.

Stiving, M., \& Winer, R. S. (1997). An empirical analysis of price endings with scanner data. Journal of Consumer Research, 24(1), 57-67.

Strahilevitz, M., \& Myers, J. G. (1998). Donations to charity as purchase incentives: how well they work may depend on what you are trying to sell. Journal of Consumer Research, 24(4), 434-446.

Thomas, M., \& Morwitz, V. (2005). Penny wise and pound foolish: the left-digit effect in price cognition. Journal of Consumer Research, 32(1), 54-64.

Voss, K. E., Spangenberg, E. R., \& Grohmann, B. (2003). Measuring the hedonic and utilitarian dimensions of consumer attitude. Journal of Marketing Research, 40(3), 310-320.

Wertenbroch, K., \& Dhar, R. (2000). Consumer choice between hedonic and utilitarian goods. Journal of Marketing Research, 37(1), 60-71.

Wilson, T. D., \& Brekke, N. (1994). Mental contamination and mental correction: unwanted influences on judgments and evaluations. Psychological Bulletin, 116(1), 117-142.

Zheng, Y., \& Kivetz, R. (2009). The differential promotion effectiveness on hedonic versus utilitarian products. Advances in Consumer Research, 36, 565. 